\title{
Por uma nova ética na publicidade infantil: alternativas frente às propostas em discussão ${ }^{1}$
}

\author{
For a new ethics in advertising directed to children: alternatives to the proposals \\ under discussion
}

\author{
Ana Paula Bragaglia ${ }^{[a]}$, Adilson Cabral ${ }^{[b]}$, Ingrid Schumann Seabra Martins ${ }^{[c]}$
}

[a] Graduada em Comunicação Social, habilitação Publicidade, pela Universidade do Estado do Rio de Janeiro (UERJ), doutora em Psicologia Social e mestre em Comunicação pela Universidade do Estado do Rio de Janeiro (UERJ), professora de Ética e Legislação Publicitária e da Comunicação na Universidade Federal Fluminense (UFF) e no Centro Universitário da Cidade (UniverCidade), Rio de Janeiro, RJ - Brasil, e-mail: apbragaglia@yahoo.com.br

[b] Doutor e mestre em Comunicação Social pela Universidade Metodista de São Paulo (UMESP), graduado em Comunicação Social, habilitação Publicidade, pela Universidade Federal Fluminense (UFF), professor do Curso de Comunicação Social e do Programa de Pós-graduação em Política Social da Universidade Federal Fluminense (UFF), Rio de Janeiro, RJ - Brasil, e-mail: acabral@comunicacao.pro.br

[c] Graduada em Comunicação Social, habilitação Publicidade \& Propaganda e Jornalismo, pela Universidade Federal Fluminense (UFF), Rio de Janeiro, RJ - Brasil, e-mail: ingrid.seabra@gmail.com

\section{Resumo}

A proposta deste artigo é sistematizar contribuições para a compreensão de uma via diferenciada sobre o debate referente à publicidade relacionada ao público infantil, polarizado entre as concepções da sociedade civil, que sugere não compreender a publicidade como atividade produtiva relevante, e o mercado, que parece não se dispor, na prática, a compreender a publicidade como atividade capaz de se pautar em princípios socialmente responsáveis. É fruto de uma pesquisa conduzida desde agosto de 2010, no âmbito do projeto "Publicidade e criança: diálogos possíveis sob o marco ético-legal", apoiado pelo Edital PIBIC/CNPq de 2010-2011, e busca, a partir do levantamento bibliográfico e documental sobre o tema, apresentar uma proposta intermediária em termos de alternativas éticas, para além, portanto, da proibição completa ou restrição de horários de veiculação.

1 Trabalho apresentado no Grupo de Trabalho 04 - Comunicação, consumo e questões geracionais, do Primeiro Encontro de GTs - Comunicon, realizado nos dias 10 e 11 de outubro de 2011. 
Palavras-chave: Publicidade infantil. Sociedade civil. Políticas de comunicação. Regulação da publicidade. Ética publicitária.

\section{Abstract}

The aim of this paper is to systematize the contributions to the understanding of a differentiated route on the debate about advertising directed to children, polarized between the views of civil society, which suggests not to understand advertising as a relevant productive activity; and the market, which does not seem to be interested, in practice, in understanding advertising activity as an activity that can be based on socially responsible principles. It is the result of a survey conducted since August 2010, under the project "Advertising and children: possible dialogues under the legal-ethical framework", sponsored by the PIBIC/CNPq Notice of 2010-2011, and that seeks, based on bibliographic and documentary researches on the topic, to present an intermediate proposal in terms of ethical alternatives to beyond the complete prohibition or restriction of advertising hours.

Keywords: Advertising directed to children. Civil society. Communication policies. Regulation of advertising. Advertising ethics.

\section{Introdução}

A proposta deste artigo é sistematizar contribuições para a compreensão de uma via diferenciada sobre o debate acerca da publicidade relacionada ao público infantil. É fruto de uma pesquisa conduzida desde agosto de 2010, no âmbito doprojeto "Publicidade e criança: diálogos possíveis sob o marco ético-legal”, apoiado pelo Edital PIBIC/CNPq de 2010-2011.

O estudo se justifica pela existência de uma temática polarizada entre duas posições antagônicas e igualmente discutíveis a respeito da publicidade relacionada às crianças (menores de 12 anos, segundo o ECAEstatuto da Criança e do Adolescente): a sociedade organizada sugere não compreender a publicidade como atividade produtiva relevante, inclusive no sentido de contribuir para a disseminação de valores positivos ao indivíduo e à população, bem como para o consumo consciente; e o mercado, por sua vez, organizado em torno de associações da cadeia produtiva da publicidade (agências, veículos e anunciantes), parece não se dispor, na prática, a compreender a publicidade como atividade capaz de se pautaremprincípios socialmenteresponsáveis.

\section{Sites relacionados}

Projetos de Lei (PLs), como 5.921/01, 29/99, 4.440/08, 6.693/09 e 4.315/08 (BRASIL,
1999, 2001, 2008a, b, 2009) e a resolução da ANVISA Agência Nacional de Vigilância Sanitária, exigindo maiores restrições à publicidade refletem o primeiro posicionamento mencionado. Dentre as propostas mais polêmicas estão a proibição completa da publicidade voltada a menores e a restrição de veiculação para um faixa horária específica, na qual a audiência seja formada principalmente por seus responsáveis adultos. Dentre os principais organismos favoráveis a tais olhares está o Instituto Alana - Projeto Criança e Consumo, instituído em 2005, tendo como principais argumentos a preocupação com estatísticas sobre aumento da obesidade infantil, sexualidade e outros comportamentos vivenciados precocemente pela criança, e constrangimento de pais e responsáveis (nagfactor), dentre outros.

Como principal representante do mercado nessa arena de debates, o Conar-Conselho Nacional de Autorregulamentação Publicitária, em vigor desde o início da década de 1980, se posiciona afirmando que suas diretrizes são suficientes para regular o setor e, além de outros argumentos, que a ação legal confronta a liberdade de expressão garantida em termos constitucionais, bem como a capacidade de intervenção e autonomia dos pais na criação de seus filhos.

De fato, diante desse cenário, o CBARP Código Brasileiro de Autorregulamentação Publicitária, concebido e adotado pelo Conar, vem 
recebendo revisões periódicas nos itens relacionados à publicidade infantil. Em 2003, mudanças nos Anexos do Código referentes a bebidas alcoólicas contemplaram principalmente as preocupações com relação a esse público. E em junho de 2006, novas medidas foram anunciadas, desta vez na própria "Seção 11 - Crianças e Adolescentes".

Como resultado, além das diretrizes já existentes (sobre a peça não estimular discriminação; não encorajar o constrangimento de pais ou responsáveis propiciado pela insistência à compra; entre outros princípios), o artigo 37 da referida seção passou a recomendar que nenhum anúncio voltado a menores de 12 anos contenha frases no imperativo voltadas a crianças (como "Peça para o seu pai") ou alguém dialogando diretamente com este público, abordagens que consistem em "apelo direto" ao público infantil (CONAR, 2011a). E a partir de 2006, por meio de alterações no seu "Anexo H - Alimentos, Refrigerantes, Sucos e Bebidas Assemelhadas", passou a recomendar também que as peças não sugiram consumo exagerado, entre outras diretrizes.

Tendo-se diretrizes como essas em vista, busca-se, neste estudo, apresentar uma proposta intermediária em termos de especificidades de abordagens publicitárias que funcionem como alternativas éticas, para além, portanto, da proibição completa ou restrição de horários de veiculação. Para tanto, serão tomadas informações, por meio de pesquisa bibliográfica (autores como Susan Linn, Noemi Momberger, Juliet Schor, Inês Vitorino Sampaio e Neil Postman) e documental (sites dos organismos envolvidos na discussão, como o Instituto Alana, o Conar, a Anvisa, bem como da Câmara dos Deputados), objetivando seguir no rastreamento de normatização em discussão e em vigor e de posicionamentos de organizações a respeito do tema, dando sequência a momentos anteriores desta pesquisa.

Além disso, de forma similar ao primeiro artigo desenvolvido neste projeto, uma metodologia empírica será adotada visando à análise de anúncios que funcionem como referência e tendência em termos de uma nova ética a ser consolidada.

Acredita-se que esse tipo de estudo intermediário, ponderador e propositivo - possa enriquecer e auxiliar a importante e atual discussão sobre o tema, otimizando os olhares polarizados ecoados até então.

\section{Publicidade infantil: práticas mercadológicas}

Em uma época em que é impossível desligar a TV sem ter assistido a pelo menos uma dezena de comerciais, cresce a preocupação sobre como as crianças serão impactadas por esse meio de comunicação. Como é fácil supor, a principal vertente pró-comunicação infantil é formada pelos profissionais da área publicitária.

Rafael Sampaio, vice-presidente executivo da Associação Brasileira de Anunciantes (ABA), defendeu, em 2010, que é melhor fazer propaganda para esse público do que deixá-lo alheio à cultura de consumo em que vivem. A declaração feita à Agência Brasil indica essa posição:

Achamos que a propaganda dirigida às crianças tem de ser muito benfeita, com altíssimo nível de responsabilidade, mas não dá mais para deixá-las em uma redoma. Como é impossível restringir o acesso das informações que as crianças recebem, a nossa tese é de que devemos fazer a publicidade para as crianças e ensiná-las a navegar em uma sociedade que tem esse excesso de ofertas (BOCCHINI, 2010).

O argumento de preparar as crianças para o mundo é recorrente aos publicitários, que acreditam que a comunicação é capaz de quebrar as proteções existentes à criança e, dessa forma, ajudá-la a "crescer sem traumas". Porém, como são esses anúncios? Há alguma definição de como deve ser uma comunicação infantil? O que se pode ver na prática?

Uma das principais características é a presença de um personagem ou mascote, que ajude a criança a identificar a marca: "O desenho simples, as cores vivas e a expressividade das emoções atribuídas a eles, fazem do mascote o porta-voz ideal da empresa para a criança" (RABELO; CARDOSO, 2011). De acordo com os autores, o fascínio por mascotes dura até os 10 anos, quando começam a ser substituídos por personalidades reais (atores, cantores etc). Para o ex-presidente da Associação Brasileira de Embalagens (ABRE), Fábio Mestriner, o uso de personagens carismáticos aumenta em média $30 \%$ as vendas de um produto (HOLSEHOLD \& COSMÉTICOS, 2003). 
O mascote escolhido deve ter em comum com a empresa seus principais atributos e valores. De acordo com a faixa etária a que se dirige, o personagem deve adotar determinado comportamento. Por exemplo, quando têm de 4 a 7 anos, as crianças possuem o hábito de cuidar, seja de uma boneca ou de um bicho de estimação - e, por conseguinte, farão o mesmo com o mascote a que assistirem na TV. Para os meninos, o interesse por super-heróis cresce, assim como para as meninas, a moda se destaca (RABELO; CARDOSO, 2011), com destaque para vestuário, maquiagem e outros itens de beleza. Ou seja, o comercial dirigido às crianças não deve incluí-las em um só target, já que tal público tem diversos estágios de desenvolvimento - e, portanto, uma comunicação somente não atinge todos.

Para o público de 3 a 7 anos, o apelo visual é o mais importante, que deve escolher um ponto como foco. Como a atenção é mais voltada para figuras, mensagens verbais devem ser evitadas. Já em relação às crianças de 8 a 12 anos, por terem os adolescentes como referência, há uma ruptura no desenvolvimento. Como forma de reconhecer essa faixa etária, os produtos direcionados a ela devem ter apelo mais realista, menos fantasioso (RABELO; CARDOSO, 2011).

De acordo com a professora de Sociologia da Faculdade de Boston, Juliet Schor, existe uma faixa etária ideal para a publicidade infantil: crianças que estão na $5^{\mathrm{a}}$ e na $6^{\mathrm{a}}$ séries (atuais $6^{\circ}$ e $7^{\circ}$ anos no ensino fundamental do Brasil) formam o "núcleo da pré-adolescência e o alvo preferido dos marqueteiros", já que "tendem a se envolver significativamente com a cultura do consumo e desenvolvem uma independência em termos de gostos e escolhas de consumo" (SCHOR, 2009, p. 155). Esse público tem, em sua maioria, entre 10 e 13 anos.

Schor considera outra característica comum à publicidade infantil. Para ela, os publicitários criam um elo com as crianças a partir da criação de "espaços utópicos livres dos pais e usam estrategicamente a dualidade das mensagens insidiosas para desenvolver o que denominamos antiadultismo. As mensagens posicionam o marqueteiro ao lado da criança, contra os pais" (SCHOR, 2009, p. 173).

Quanto a este fato, basta perceber que é rara a presença da figura de um adulto em um comercial infantil. Geralmente o que se vê são crianças e alguma interação eletrônica. Na maioria das vezes em que adultos aparecem são como figuras comuns ao imaginário infantil, como o sorveteiro, por exemplo.

Para a professora Eliane Karsaklian, não há mais dúvidas de que as crianças realmente gostam de propagandas. O interesse surge pelo que é mostrado, como "as cores, os movimentos, as músicas, as personagens, tudo faz com que a atenção das crianças seja raramente desviada da tela da TV" (KARSAKLIAN, 2000, p. 222). Funciona como um mundo onírico e, por isso, para que a lembrança do produto permaneça na mente da criança, é necessário que ele apareça dentro dessa história, e não somente no fim do comercial. Em sua obra, Karsaklian cita outras características da propaganda infantil, divulgadas anteriormente por N. Feuerhahn (1978), como

1) A estrutura do discurso publicitário assemelha-se àquela dos programas infantis (linguagem simples, sequências rápidas...);

2) O caráter extremamente estereotipado das personagens e das situações, o que garante às crianças a segurança de perceber um mundo sem problemas e de soluções fáceis. A criança tende a rejeitar programas muito realistas justamente por causa de sua natureza brutal;

3) Os objetos apresentados na propaganda são bons por definição e isso dá segurança à criança;

4) O fato de se repetir dá à criança a sensação de perenidade e de estabilidade, conservando um ambiente que lhe é familiar (FEUERHAHN apud KARSAKLIAN, 2000, p. 222-223).

Segundo Gorn e Goldberg (1980), citados por Karsaklian (2000, p. 226), essa repetição deve ser de três vezes - assim como ocorre com os adultos -, pois quando expostas cinco vezes ao comercial a criança tende a rejeitá-lo.

Para Karsaklian, o interesse pela propaganda começa a diminuir aos 10 anos, quando a criança já compreende os objetivos comerciais envolvidos. No entanto, um recenseamento citado pela professora afirma que é possível manter sua atenção caso se consiga divertir a criança. Outros fatores que auxiliam são o uso de desenhos animados, canções, presença de animais, principalmente se 
forem personificados, e roteiros com bastante ação ou com valores representativos em evidência (ser forte, inteligente, amigo etc.). A pesquisa apontou também outra diferença de gosto pela faixa etária, em que os mais velhos apreciam propagandas que abordam valores culturais modernos, enquanto os mais novos se interessam por comerciais em que o protagonista éidoso (KARSAKLIAN, 2000, p. 223).

Outra pesquisa citada pela autora retrata a importância de se conseguir a atenção das mães para o comercial, pois "determinada marca aumenta suas chances de ser adquirida quando a mãe tem familiaridade com ela, quando ela se sente bem informada a seu propósito" (KARSAKLIAN, 2000, p. 238).

Outro comportamento detectado foi encontrado no site do Instituto Brasileiro do Consumidor (IDEC). Em 2009, o site anunciou a divulgação de um relatório sobre o comportamento dos grandes anunciantes de produtos infantis, realizado pela Consumers International. O resultado foi o aumento da presença comercial do computador no dia a dia das crianças. Isso explica a resolução dos principais anunciantes de veicular seus produtos na internet, como informado a seguir:

Jogos interativos, clubes de internet e sites ao estilo do MySpace são alguns dos recursos utilizados para atrair as crianças para a exposição à publicidade. Mensagens direcionadas aos pais alegam os jogos online têm caráter "educativo" e que os sites são "seguros" (IDEC, 2009).

No entanto, além do que se costuma utilizar em publicidade infantil, há também o que não se recomenda. O Conselho de Autorregulamentação Publicitária - Conar - não aceita, por exemplo, que haja apelo imperativo de consumo em anúncios desse gênero. Nas decisões expostas no site, nota-se que é o principal problema das peças dirigidas a esse público e que, quando o Conselho julga casos com tal característica, delibera pela alteração do texto (CONAR, 2011d).

O código do Conar também traz uma seção exclusiva a crianças e jovens (de número 11), em que orienta as agências a como fazer propaganda para esse público. O primeiro inciso do artigo $37 \mathrm{diz}$ que os anúncios devem ter cuidados com a segurança e boas maneiras, além de não desmerecervalores sociais positivos (como amizade, honestidade e justiça), provocar qualquer tipo de discriminação, associar crianças e adolescentes a situações incompatíveis com sua condição, impor a noção de que o consumo do produto proporcione superioridade, provocar constrangimento aos responsáveis como forma de ocasionar o consumo, empregar crianças e adolescentes para vocalizar apelo direto, recomendação ou sugestão de uso ou consumo, utilizar formato jornalístico, apregoar que o produto tenha características peculiares que, na verdade, são encontradas nos concorrentes, e utilizar situações de pressão psicológica ou violência. (CONAR, 2011a).

O segundo inciso do mesmo artigo diz respeito aos produtos que se destinam a crianças e adolescentes. Nesses casos, os anúncios deverão procurar contribuir para o desenvolvimento positivo das relações que envolvam o público-alvo, respeitar a dignidade, ingenuidade, credulidade, inexperiência e o sentimento de lealdade das crianças, dar atenção especial às suas características psicológicas, obedecer a esses cuidados para evitar eventuais distorções psicológicas nos modelos publicitários e no público e abster-se de estimular comportamentos socialmente condenáveis. Assim, caso algum anúncio publicitário contrarie algum dos itens anteriores poderá ser julgado pelo Conar e ter seu conteúdo alterado ou até mesmo suspenso (CONAR, 2011a).

\section{Práticas mercadológicas na mira}

É notória a quantidade de autores e instituições que criticam como é produzida a publicidade infantil atualmente. Um dos argumentos é o fato de as crianças ainda não terem capacidade de discernir o que é propaganda e o que é programa televisivo e que, por isso, por exemplo, aoverem um personagem de desenho animado em um anúncio, confundem o consumo do produto com algo verossímil realizado pela animação.

Outro ponto discutido é que a criança não conhece o objetivo de vendas que pauta a propaganda. Ao não saber a intenção de um comercial, o público infantil confia na mensagem sem suspeitar de nada.

Segundo a advogada Noemí Momberger, entre os 4 e 5 anos de idade, a criança já consegue diferenciar de forma razoável comerciais de programas, ainda que não seja capaz de identificar criticamente seu conteúdo - capacidade conquistada aproximadamente entre os 7 e 8 anos (MOMBERGER, 2002, p. 33-34). 
O uso de personagens conhecidos das crianças também é criticado pela pesquisadora, pois o público infantil tende a

aceitar prontamente as alegações e apelos de produtos caros, especialmente aqueles anunciados por personagens e atores de quem gostam e nos quais confiam. [...] As crianças não identificam a publicidade como tal, e como são leais, confiam nos apelos de seus personagens e atores preferidos de programas infantis, portanto, suscetíveis de serem influenciadas pelos comerciais (MOMBERGER, 2002, p. 35).

Juliet Schor aponta o problema de se anunciar para o público infantil a partir do depoimento dado por uma executiva sênior e mãe solteira. Sob o pseudônimo de Susan Davies, a entrevistada afirmou que a indústria da propaganda não tem responsabilidade moral suficiente para anunciar às crianças.

Nas agências, os marqueteiros têm receio de confrontar-se com os clientes. Nas empresas, existe também uma insuficiência de responsabilidade. E por todo lado a pressão por realizar lucros sobrepuja a necessidade de fazer o bem às crianças (SCHOR, 2004, p. 199).

A professora brasileira Inês Sampaio partilha desta opinião. Para ela, o crescimento do consumo infantil e sua valorização é uma tendência global: "a publicidade transforma crianças em vorazes consumidores, com implicações na definição das grades de programação televisiva" (SAMPAIO, 2009, p. 14). Um exemplo dessa transformação seria o uso de merchandisings em programas infantis, que o Ministério Público Federal (MPF) já considera ilegal - o comunicado foi feito a partir de nota divulgada em junho deste ano, que conclui da seguinte forma:

Diante de todo o exposto, o Grupo de Trabalho Comunicação Social, vinculado à Procuradoria Federal dos Direitos do Cidadão, entende que o merchandising destinado ao público infantil, mormente na forma testemunhal, é ilegal, de modo que as infrações administrativas eventualmente apuradas nos procedimentos em curso no DPDC poderão, em tese, ensejar também responsabilização civile/ ou penal (MPF, 2011).
Dependendo da faixa etária, a criança não consegue diferenciar o comercial do programa, segundo o MP e os demais atores que criticam essa prática. O merchandising vai de encontro ao artigo 37 do Código de Defesa do Consumidor (CDC, 1990), que considera abusiva a publicidade que se aproveita "da deficiência de julgamento e experiência da criança" (CDC, 1990).

Sampaio também cita outros problemas causados pela propaganda em crianças, como o aumento da obesidade infantil (graças à construção de hábitos alimentares não saudáveis) e a escolha de um modelo de vida e consumo como certos (o que causa a sensação de exclusão em muitas crianças que não podem consumir determinados produtos). Outros autores também citam a sexualidade precoce como consequência negativa da propaganda dirigida a crianças.

A autorregulamentação publicitária também é questionada. Como é feita pelo próprio mercado, Sampaio a vê como "uma tentativa do próprio sistema publicitário de evitar a ação reguladora do Estado", além de ser "insuficiente para assegurar a proteção da infância” (SAMPAIO, 2009, p. 20).

O Instituto Alana, organização não governamental sem fins lucrativos, também tem dúvidas quanto à funcionalidade do Conar. Tamara Gonçalves, advogada do Instituto, reconhece a importância do Conselho, assim como sua limitação: "Ele não é um órgão do Estado e, portanto, não pode impor sanções punitivas e repressivas. Se a publicidade sai do ar, ele não tem mais nenhum poder de atuação" (CUNHA, 2011).

O professor de Ética da ECA/USP e conselheiro do Projeto Criança e Consumo (do Instituto Alana), Clóvis de Barros Filho, acredita que o Conar não é eficaz em julgar as práticas publicitárias, mas sim os assuntos internos aos publicitários, como a regulamentação das relações e o julgamento de conflitos entre os profissionais.

Por isso, deixar para os publicitários a prerrogativa da decisão sobre os limites de sua própria atuação-na relação que mantêm coma sociedade como um todo - é desrespeitar o princípio da terceridade da justiça. Seria como entregar uma creche aos cuidados de pedófilos, analogia típica de minha formação em Direito. É presumir altruísmo e abnegação incompatíveis com o mundo da técnica, com a lógica do capital e com 
os rigores da competição no mercado para o qual trabalham (BARROS FILHO, 2011).

Ao observar as decisões do Conar sobre alguns anúncios publicitários, é possível perceber o que mais ocorre na propaganda atualmente. Em maio deste ano, por exemplo, o Conselho decidiu pela sustação do comercial "Dia dos Fuzarkas Renner", que apontou a existência de sugestão de consumo vocalizada por criança, assim como apelos diretos e persuasivos de consumo dirigidos ao público infantil. As frases questionadas foram: "Eu quero um DVD da Disney", "A cada R \$ 60 em compras ganhe um DVD da Disney" e "Concorra a muitos iPods" (CONAR, 2011d).

No mesmo mês, o Conar decidiu pela alteração de outros dois comerciais. O primeiro é da empresa Grow, com o anúncio "Super Trunfo - Eu quero todos". A alegação foi a presença de apelo imperativo de consumo na frase "Eu quero, eu quero todos. Eu quero muito", que estava exposta no cenário. O segundo foi do refrigerante Dolly (anunciante Dettal), com o vídeo “Dolly Verão 2011”, que fala em jingle para se beber mais líquido, exatamente quando exibe bonecos de animação bebendo o refrigerante, o que poderia induzir as crianças a fazerem o mesmo (CONAR, 2011d,).

Nas decisões de março de 2011, também houve sustação de comercial de outra loja de departamentos. Para o relator do Conar, o anúncio "Dia das Crianças Riachuelo" desrespeitou o código do Conselho ao empregar a apresentadora mirim Maísa como porta-voz do comercial (CONAR, 2011e). Ainda em março, o anúncio "Samsung Celular Beat Mix - Princesa" recebeu a decisão de alteração do texto, por afirmar que a menina que possuir o aparelho será chamada de princesa na escola. Com a decisão, a Samsung deve suprimir essa frase (CONAR, 2011e).

Em dezembro de 2010, o comercial "Sustagen Kids - Fortaleça a saúde do seu filho todos os dias" também recebeu a decisão de alteração pelo Conar. O problema da peça foi a mensagem deseducativa que expôs, ao mostrar crianças rejeitando legumes, além da frase "um copo de leite com Sustagen Kids oferece $100 \%$ do ferro, zinco e vitamina C que o seu filho precisa", que contraria a informação dada pela locução de que o produto funciona como um complemento da alimentação (CONAR, 2011c).

No mês anterior, o anúncio "Nerf - Hasbro" foi sustado por, na visão do relator do Conar, sugerir violência, guerra e combate. $\mathrm{Na}$ peça, cujo objetivo era divulgar um lançador de dados, há crianças e adolescentes manuseando brinquedos que simulavam armas de fogo (CONAR, 2010b).

A partir dessa pequena relação de exemplos, percebe-se que háainda muitas propagandas que vão de encontro aos códigos e leis vigentes no país e denotam a necessidade de se compreender melhor a eficácia do mecanismo de autorregulamentação no país.

\section{Nova ética: tendências e referências}

Até o momento, o debate a respeito da publicidade dirigida ao público infantil não encontrou solução satisfatória. $\mathrm{Na}$ tentativa de melhorar o cenário, propõe-se aqui uma nova ética, tomando por base o que já pode ser visto em alguns anúncios televisivos. Atualmente, já é possível identificar comerciais que não vão de encontro a nenhuma queixa já feita e apontam para novos modos de relacionamento entre agências, clientes e público.

Um exemplo é o comercial do "Danoninho Ossos Fortes", que se dirige às mães, tem homem como locutor e traz a presença de adultos no vídeo (no caso a própria mãe). Trata-se de um anúncio recente $^{2}$. No comercial, crianças brincam em um parquinho e, como toda brincadeira infantil, caem bastante. O locutor do anúncio diz "Cair e levantaré a maior lição que seu filho pode ter. Mas para isso é importante terossos fortes. Nesta fase conte também com Danoninho [...]". Nesse momento, aparece a mãe alimentando seus filhos com Danoninho para, em seguida, brincar com eles no parquinho. No comercial também aparece o cachorro da família brincando com as crianças.

Outro exemplo de comercial com narrador homem e presença de adulto, dessa vez na forma de pai, é o carro Supremus Maximus New Generation, da Estrela (disponível no site da empresa ${ }^{3}$ ). Nele,

\footnotetext{
2 Publicado em abril de 2010. Disponível em: <http://www.youtube.com/watch?v=8X5ekX9YQgw\&NR=1>. Acesso em: $1^{\circ}$ set. 2011.

3 Publicado em 30 de setembro de 2009. Disponível em: <http://www.youtube.com/watch?v=x3ejDC54tC8\&feature=player_ embedded\#! >. Acesso em: $1^{\circ}$ set. 2011.
} 
pai e filho interagem brincando ao ar livre com o brinquedo anunciado. Ainda com relação à Estrela, há outro comercial que também condiz com princípios de uma nova ética possível. Este se refere aos três jogos clássicos da empresa (Banco Imobiliário, Detetive e Jogo da Vida), mostrando uma família completa (pai, mãe e um casal de filhos) jogando e se divertindo juntos.

Ambas as peças têm um valor positivo não só por contarem com a presença de adultos, mas também por remeterem a uma postura de aproximação entre pais e filhos numa era em que imperam as babás (televisivas, inclusive).

No entanto, a presença de adultos nas peças não é majoritária no cenário publicitário do Brasil. Grande parte dos comerciais ainda não traz adultos (ou quando o fazem é em algum papel do imaginário infantil), tem locutores infantis e se dirige especificamente às crianças. Porém esse é um comportamento que vem mudando, na medida em que muitas agências e anunciantes já sabem que é possível atingir o objetivo de vendas fazendo o oposto a essas características.

Em 2009, a Associação Brasileira de Indústria de Alimentos (ABIA) e a Associação Brasileira de Anunciantes (ABA) formalizaram uma espécie de código de conduta sobre como empresas alimentícias deveriam comunicar seus produtos ${ }^{4}$. Nessa carta-compromisso, 24 empresas e grupos líderes da área de alimentos e bebidas se comprometeram a não veicular publicidade dirigida a menores de 12 anos em veículos de massa (televisão, rádio, mídia impressa e internet) em que $50 \%$ ou mais do montante da audiência ${ }^{5}$ seja constituída por esse público, além de não realizar promoções de caráter promocional em escolas. Pelo documento, nota-se que a publicidade infantil seria, para os signatários, determinada pelo tipo e abrangência de audiência e não por um conteúdo específico. Apesar disso, sobre esse quesito, a carta aponta uma exigência, das empresas adeptas, de se comprometerem "a promover, no contexto de seu material publicitário e promocional, quando aplicável, práticas e hábitos saudáveis, como alimentação balanceada e/ou a realização de atividades físicas", cuidados esses também já presentes no CBARP, do Conar (ABIA; ABA, 2009). Isso explica o fato de algumas empresas, como a Nestlé e a Coca Cola, terem lançado comunicados públicos, afirmando que não mais direcionam suas campanhas ao público infantil, mas a seus pais e destacando uma reorientação estratégica de associar conteúdos educativos sobre saúde, educação alimentar e prevenção de doenças por meio de suas peças e veículos de comunicação (DE SALVI; GUERRA, 2009).

Provavelmente, ao mudar o público-alvo de comerciais de produtos infantis para os adultos, irão ocorrer mudanças de formato, linguagem, personagens, etc. No entanto, produtos nocivos ou com informação equivocada demandam também a atenção de organismos de fiscalização na área, como a Anvisa, que são também uma instância necessária à complementação dessas políticas. A perfeita compreensão de cada agente - anunciantes, agências, Estado e, também, a sociedade - poderá contribuir para a adoção de uma regulação para a publicidade socialmente responsável destinada às crianças.

\section{Considerações finais}

Este artigo se insere num projeto de pesquisa que se motiva pela necessidade de incidir no debate público sobre um consenso possível em torno de uma alternativa ao PL 5.921/01, que busca regulamentar o setor. O paper teve seu primeiro momento na análise de comerciais veiculados ao público infantil em canais que se destinam predominantemente a esse público e prosseguiu na análise dos posicionamentos das organizações sociais e de mercado em relação aos limites da autorregulamentação em vigor e às possíveis tentativas de regulamentação.

Compreende a publicidade (incluindo a socialmente responsável, como as três peças descritas no tópico anterior) como incompatível na sua interlocução com o público infantil, ou seja, tendo-o como público-alvo ao dirigir mensagens diretamente a tal audiência, ao despir-se da figura de pais e outros responsáveis nas peças. No entanto,

\footnotetext{
${ }^{4}$ No entanto, a Justiça Federal de Brasília mantém liminar que libera o cumprimento da norma por parte das associadas da ABIA (Kellogg's, McDonald's, Danone, entre outras).

5 Naturalmente, os produtos adequados a critérios nutricionais recomendados a crianças ficam fora dessa regra.
} 
não condena a publicidade relacionada a produtos e serviços destinados ao público infantil que estimule diálogos com seus responsáveis e que aponte, inclusive, para mensagens positivas que transcendam os próprios atributos do produto e outros argumentos hedonistas/individualistas adequados à retórica do discurso persuasivo.

A ausência de argumentação crítica a partir da publicidade causa estranheza quanto à incapacidade de uma defesa da atividade que se paute por esse seu caráter social. A polarização do debate tal como estabelecida leva a crer na impressão de que organizações sociais acreditam que publicidade é um mal que deva ser limitado tanto quanto possível, causando reações que equivalem tais argumentos à censura, e organizações de mercado, por sua vez, se pautam na indefensável liberdade de expressão comercial, afirmada como superior à defesa de direitos humanos na qual o país se situa.

\section{Referências}

ASSOCIAÇÃO BRASILEIRA DE INDÚSTRIA DE ALIMENTOS - ABIA; ASSOCIAÇÃO BRASILEIRA DE ANUNCIANTES - ABA. Indústrias de alimentos assumem compromisso espontâneo sobre publicidade dirigida às crianças. São Paulo: ABIA, 2009.

BARROS FILHO, C. de. Autorregulamentar a publicidade infantil?. 2011. Disponível em: <http://www. alana.org.br/CriancaConsumo/NoticiaIntegra.aspx? id $=8303$ \&origem $=23>$. Acesso em: 17 ago. 2011.

BOCCHINI, B. Maioria dos pais concorda com restrição à publicidade infantil. Agência Brasil. Março de 2010. Disponível em: < http:/ / www.direitoacomunicacao.org.br/content.php? option $=\mathrm{com}_{-}$ content\&task $=$ view\&id $=6303>$. Acesso em: 24 jul. 2011.

BRASIL. Projeto Lei n. 29/99. Dispõe sobre regulamentação de anúncios publicitários em horários de programação infanto-juvenil. Brasília, 1999. Disponível em: < http://www.camara.gov.br/proposicoesWeb/fic hadetramitacao?idProposicao $=14955>$. Acesso em: 23 jul. 2011.
BRASIL. Projeto Lei n. 5.921 de 12 de dezembro de 2001. Próbe a publicidade e propaganda para a venda de produtos infantis. Brasília, 2001. Disponível em: $<$ http://www.camara.gov.br/proposicoesWeb/fichadetram itacao?idProposicao=43201 > . Acesso em: 23 jul. 2011.

BRASIL. Projeto Lei n. 4.440/08. Trata da regulamentação do artigo $8^{\circ}$ da $\mathrm{CF}$, do custeio sindical e da organização sindical nolocal de trabalho. Aassessoria parlamentar e o corpo técnico do DIAP providenciarão uma análise mais detalhada do projeto e também um parecer técnico. Brasília, 2008a. Disponível em: $<$ http://www.anabb.org.br/mostraPaginaCorpo.asp?co $\mathrm{dPagina}=32520 \&$ codServico $=4 \&$ tituloPagina $=$ Ter $\% \mathrm{C}$ 3\%A7a-Feira >. Acesso em: 23 jul. 2011.

BRASIL. Projeto Lei n. 4.440/08. Aumenta a pena prevista em caso de divulgação de publicidade que sabe ou deveria saber enganosa ou abusiva, incorrendo o infrator no dobro da pena quando a publicidade for dirigida a crianças. Brasília, 2008b. Disponível em: $<$ http://www.camara.gov.br/proposicoesWeb/fichadetra mitacao?idProposicao=416023 > . Acesso em: 23 jul. 2011.

BRASIL. Projeto Lei n. 6.693/09. Dispõe da obrigatoriedade do uso de proteção adesiva, plástica e descartável, na região da boca e nariz, nos capacetes utilizados pelos passageiros transportados por mototaxistas, em Campo Grande. Campo Grande, 2009. Disponível em: <http://profjoaorocha.blogspot.com.br/2011/02/ aprovado-projeto-de-lei-de-joao-rocha.html $>$. Acesso em: 23 jul. 2011.

CÓDIGO de Defesa do Consumidor. 1990. Disponível em:<http://www.planalto.gov.br/ccivil_03/leis/18078.htm>. Acesso em: 17 ago. 2011.

CONSELHO NACIONAL DE AUTORREGULAMENTAÇÃO PUBLICITÁRIA - CONAR. Código. Disponível em: <http://conar.org.br/>. Acesso em: 29 ago. 2011a.

CONSELHO NACIONAL DE AUTORREGULAMENTAÇÃO PUBLICITÁRIA - CONAR. Decisões Novembro 2010. Disponível em: <http://conar.org. br/>. Acesso em: 29 ago. 2011b.

CONSELHO NACIONAL DE AUTORREGULAMENTAÇÃO PUBLICITÁRIA - CONAR. Decisões Dezembro2010. Disponível em: <http:// conar.org.br/>. Acesso em: 29 ago. 2011c. 
BRAGAGLIA, A. P.; CABRAL, A.; MARTINS, I. S. S.

CONSELHO NACIONAL DE AUTORREGULAMENTAÇÃO PUBLICITÁRIA - Conar. Decisões Março 2011. Disponível em: <http://conar.org.br/>. Acesso em: 24 jul. 2011d.

CONSELHO NACIONAL DE AUTORREGULAMENTAÇ̃̃O PUBLICITÁRIA - Conar. Decisões Maio 2011. Disponível em: <http://conar.org.br/>. Acesso em: 29 ago. 2011e.

CUNHA, A. R. Ministério Público considera merchandising infantililegal. Disponível em: $<$ http: / $/$ www. direitoacomunicacao.org. $\mathrm{br} /$ content.php?option $=\mathrm{com}_{-}$ content\&task=view\&id $=7928>$. Acesso em:30 ago. 2011 .

DE SALVI, R.; GUERRA, R. Proibir é a solução? A polêmica sobre a publicidade infantil chega ao Congresso. 2009. Disponível em: <http://www.revistapropaganda. com.br/materia.aspx?m=196>. Acesso em: 11 set. 2011.

HOLSEHOLD \& COSMÉTICOS. Brincadeiras lucrativas. Revista H\&C, Ano IV, n. 22, 2003. Disponível em: $<$ http://www.freedom.inf.br/revista/HC22/cosmeticos. asp >. Acesso em: 24 jul. 2011.

INSTITUTO BRASILEIRO DE DEFESA DO CONSUMIDOR - Idec. Publicidade infantil de alimentos: novas mídias, velhos truques. Março de 2009. Disponível em: <http://www.idec.org.br/emacao.asp?id=1735>. Acesso em: 24 jul. 2011.

KARSAKLIAN, E. Comportamento do consumidor. São Paulo: Atlas, 2000.
MINISTÉRIO PUBLICO FEDERAL. Nota técnica: publicidade infantil em programações televisivas. Junho de 2011. Disponível em: <http://pfdc.pgr.mpf.gov.br/ institucional/grupos-de-trabalho/comunicao-social/ temas-trabalhados/propaganda-dirigida-publico-infantil/ atuacao-do-mpf-1/nota-tecnica-merchandising $>$. Acesso em: 28 ago. 2011.

MOMBERGER, N. F. A publicidade dirigida às crianças e adolescentes: regulamentações e restrições. Porto Alegre: Memória Jurídica, 2002.

RABELO, A.; CARDOSO, A. Estratégia de marcas e personagens. Disponível em: <http:/ / www.marketinginfantil.com.br/>. Acesso em: 24 jul. 2011.

SAMPAIO, I. Publicidade e infância: uma relação perigosa. In: VEEET, V. (Org.). Infância e consumo: estudos no campo da comunicação. Brasília: Andi; Instituto Alana, 2009. p. 9-21.

SCHOR, J.Nascidos para comprar: uma leitura essencial para orientarmos nossas crianças na era do consumo. São Paulo: Gente, 2009.
Recebido: 25/02/2012

Received: 02/25/2012

Aprovado: 30/05/2012 Approved: 05/30/2012 